\title{
PENGARUH KOMUNIKASI INTERPERSONAL DAN SUPERVISI KEPALA SEKOLAH TERHADAP KINERJA GURU SMP NEGERI SEKECAMATAN SUNGAI APIT KABUPATEN SIAK
}

\author{
Asri Seni Vinal 1) \\ Makhadalena ${ }^{2)}$ \\ Rr. Sri Kartikowati ${ }^{3)}$ \\ 1) Post Graduate Student of Riau University \\ 2) Lecturer of Education Management Study Programme PPs University of Riau \\ 3) Lecturer of Education Management Study Programme PPs University of Riau
}

\begin{abstract}
:
This study aims to find out about the influence of independent variables with dependent variables. (1) Interpersonal communication and supervision by school principals on the performance of teachers of SMP Negeri in Sungai Apit District. (2) Interpersonal communication on the performance of teachers of SMP Negeri in Sungai Apit District. (3) Supervision of school principals on the performance of state junior high school teachers in Sungai Apit sub-district. Through the distribution of instruments to 85 teachers of the SMP Negeri in Sungai Apit sub-district using proportional random sampling techniques. The instrument used to collect data about teacher performance, interpersonal communication, and supervision of school principals using a questionnaire. Item validity was tested using the Pearson product moment formula for teacher performance variables, interpersonal communication, and academic supervision. The instrument reliability coefficient was calculated using the Cronbach Alpha formula. The results showed a significant influence between (1) interpersonal communication and supervision of school principals on teacher performance by $44.6 \%$, (2) interpersonal communication on teacher performance by 5.9\%, (3) supervision of school principals on teacher performance by $259 \%$.
\end{abstract}

Keywords : Interpersonal Communication, Principal Supervision, and Teacher Performance 


\begin{abstract}
ABSTRAK
Penelitian ini bertujuan untuk mengetahui tentang adanya pengaruh antar variabel bebas dengan vaiabel terikat. (1) Komunikasi interpersonal dan supervisi kepala sekolah terhadap kinerja guru SMP Negeri seKecamatan Sungai Apit. (2) Komunikasi interpersonal terhadap kinerja guru SMP Negeri seKecamatan Sungai Apit. (3) Supervisi kepala sekolah terhadap kinerja guru SMP Negeri seKecamatan Sungai Apit. Melalui penyebaran instrumen kepada 85 orang guru SMP Negeri seKecamatan Sungai Apit dengan menggunakan teknik random sampling proporsional. Instrumen yang digunakan untuk mengumpulkan data tentang kinerja guru, komunikasi Interpersonal, dan supervisi kepala sekolah dengan menggunakan angket. Validitas butir di uji dengan menggunakan rumus pearson product moment untuk variable kinerja guru, komunikasi interpersonal, dan supervisi akademik. Koefisien reliabilitas instrument dihitung dengan menggunakan rumus Alpha Cronbach. Hasil penelitian menunjukkan adanya pengaruh signifikan antara (1) komunikasi interpersonal dan supervisi kepala sekolah terhadap kinerja guru sebesar 44,6\%, (2) komunikasi interpersonal terhadap kinerja guru sebesar $5,9 \%$, (3) supervisi kepala sekolah terhadap kinerja guru sebesar 25,9\%.
\end{abstract}

Kata Kunci : Komunikasi Interpersonal, Supervisi Kepala Sekolah, dan Kinerja Guru

\section{PENDAHULUAN}

Guru sangat menentukan keberhasilan peserta didik, terutama dalam kaitannya dengan proses belajar mengajar. Guru merupakan pemegang peranan utama dalam proses belajar mengajar. Proses belajar mengajar merupakan suatu proses yang mengandung serangkaian perbuatan guru dan peserta didik atau dasar hubungan timbal balik yang berlangsung dalam situasi edukatif untuk mencapai tujuan tertentu.

Sebaik apapun kurikulum dan sistem pendidikan yang ada, tanpa didukung kemampuan guru, semuanya akan sia-sia. Guru kompeten dan efektif, tanggung jawab utamanya mengawal perkembangan peserta didik sampai suatu titik maksimal. Tujuan akhir seluruh proses pendampingan guru adalah tumbuhnya pribadi dewasa yang utuh. Tanpa guru kurikulum itu hanyalah benda mati yang tiada berarti.

Untuk mencapai tujuan yang diinginkan maka diperlukan kinerja guru yang optimal. Kinerja merupakan suatu kemampuan kerja atau prestasi kerja yang diperlihatkan oleh seorang pegawai untuk memperoleh hasil kerja yang optimal. Kinerja guru pada dasarnya merupakan kinerja atau unjuk kerja yang dilakukan oleh guru dalam melaksanakan tugasnya sebagai pendidik. Kualitas kinerja guru akan sangat menentukan pada kualitas hasil pendidikan, karena guru merupakan pihak yang paling banyak bersentuhan langsung dengan siswa dalam proses pendidikan/pembelajaran di sekolah.

Kinerja seorang guru dikatakan baik jika guru telah melakukan unsureunsur yang terdiri dari kesetiaan dan komitmen yang tinggi pada tugas mengajar, menguasai dan mengembangkan bahan pelajaran, kedisiplinan dalam mengajar dan tugas lainnya, kreativitas dalam pelaksanaan pengajaran, kerjasama dengan semua warga sekolah, kepemimpinan yang menjadi panutan siswa, kepribadian yang baik, jujur, dan objektif dalam membimbing siswa, serta tanggung jawab terhadap tugasnya. Membahas 
masalah kualitas dari kinerja guru tidak terlepas dari pencapaian hasil belajar. Hal ini karena kinerja guru sangat menentukan keberhasilan proses belajar yang efektif dan efisien sehingga tujuan pendidikan dapat tercapai dan terwujud dari hasil belajar siswa yang baik yang pada akhirnya dapat mencetak lulusan yang berkualitas.

Kinerja guru dipengaruhi oleh beberapa faktor yang meliputi faktor personal atau individual, meliputi unsur pengetahuan, keterampilan (skill), kemampuan, kepercayaan diri, motivasi, dan komitmen yang dimiliki oleh tiap individu guru, faktor kepemimpinan, meliputi aspek kualitas manajer dan team leader dalam memberikan dorongan, semangat, arahan, dan dukungan kerja pada guru, faktor tim, meliputi kualitas dukungan dan semangat yang diberikan oleh rekan dalam satu tim, kepercayaan terhadap sesama anggota tim, dan keeratan anggota tim, faktor sistem, meliputi sistem kerja, fasilitas kerja yang diberikan oleh pimpinan sekolah, proses organisasi (sekolah) dan kultur kerja dalam organisasi (sekolah), dan faktor kontektual (situasional), meliputi tekanan dan perubahan lingkungan eksternal dan internal. Salah satunya yaitu komunikasi interpersonal.

Peningkatan kinerja guru sesuai dengan Sistem Manajemen Mutu ISO 9001:2008 dapat dilakukan melaui komunikasi interpersonal. Komunikasi yang terjadi di sekolah terutama antara kepala sekolah, guru dan karyawan, jika dilakukan secara baik dan intensif, maka akan mempengaruhi sikap guru dalam menjalankan tugasnya seharihari, yang berujung pada peningkatan kinerjanya di sekolah. Sebaliknya, apabila proses komunikasi yang terjadi di sekolah kurang baik, maka dapat menimbulkan sikap yang otoriter. Terutama ketika terjadi perbedaan pendapat yang berkepanjangan antara kepala sekolah dan guru. Jika hal itu terjadi, maka dapat berdampak pada kinerja guru yang kurang maksimal. Proses komunikasi diperlukan adanya keterbukaan dan kerjasama yang harmonis antara kepala sekolah dan guru, agar tujuan yang ingin dicapai oleh lembaga pendidikan tersebut dapat tercapai. Hakikat dari hubungan interpersonal ini adalah ketika berkomunikasi, komunikator bukan hanya menyampaikan isi pesan, tetapi juga menentukan bagaimana bobot dari kadar hubungan interpersonal tersebut.

$$
\text { Selain dari memiliki }
$$

kemampuan komunikasi interpersonal yang baik, hal lain yang turut mempengaruhi kinerja seorang guru adalah supervisi kepala sekolah. Supervisi kepala sekolah merupakan variabel yang berasal dari luar diri guru namun memiliki peran yang penting dalam mempengaruhi kinerja guru. Supervisi merupakan bentuk perhatian dan pengarahan dari kepala sekolah untuk senantiasa meningkatkan tanggung jawab guru akan tugas dan kewajibannya. Semakin intensif supervisi kepala sekolah baik secara kualitas maupun secara kuantitas, maka guru akan memiliki perhatian pada tugas dan tanggung jawab yang dipikulnya. Kemampuan komunikasi interpersonal dan supervisi kepala sekolah apabila mampu disinergikan akan memberi dampak positif terhadap kinerja guru. Kepala sekolah tidak hanya memberikan pengarahan dan pengawasan saja kepada guru, namun ia juga mampu mengkomunikasikan dan bisa diterima oleh guru yang memiliki komunikasi interpersonal yang baik pula tentang hal-hal yang penting guna menciptakan suasana kerja yang kondusif dan dinamis. Suasana yang demikian itu pada giliranya akan mampu mendorong semangat berkarya 
guru yang pada gilirannya dapat memacu kinerjanya.

Fenomena tentang rendahnya kinerja guru disebabkan oleh lemahnya komunikasi interpersonal guru yang peneliti temui saat observasi awal peneliti dan diskusi dengan pengawas SMP Negeri seKecamatan Sungai Apit, beliau mengatakan, dibeberapa SMP Negeri di Kecamatan ini terindikasi beberapa guru yang memiliki kinerja rendah seperti: 1) kurang mampu melaksanakan pembelajaran dengan baik. Keadaan ini membuat guru tidak mampu menguasai kelas dengan baik sehingga murid jadi kurang fokus dan sering meribut dalam kelas. 2) tidak mampu memahami karateristik siswa dengan baik, keadaan ini membuat proses pembelajaran tidak kondusif sebab guru tidak bisa memberikan pemahaman pada murid sesuai dengan batas kemampuan mereka, dan 3) kesulitan dalam melakukan evaluasi dan memanfaatkan hasil untuk kepentingan pembelajaran.

Fenomena selanjutnya yang peneliti temui dari hasil kunjungan dan diskusi dengan pengawas SMP Negeri di Kecamatan Sungai Apit, peneliti mendapatkan data supervisi yang dilakukan kepala sekolah di SMPnya masing-masing. Dari tujuh SMP Negeri yang ada di Sungai Apit hanya ada empat SMP yang setiap kepala sekolahnya sering melakukan supervisi kepada guru dan melakukan tinjauan kekelas saat proses pembelajaran sedang berlangsung.

Berdasarkan latar belakang masalah yang telah diuraikan di atas, maka masalah penelitian dirumuskan sebagai berikut :

1. Apakah komunikasi interpersonal dan supervisi kepala sekolah secara bersama-sama berpengaruh terhadap kinerja guru SMP Negeri
seKecamatan Sungai Apit Kabupaten Siak?

2. Apakah komunikasi interpersonal berpengaruh terhadap kinerja guru SMP Negeri seKecamatan Sungai Apit Kabupaten Siak ?

3. Apakah supervisi kepala sekolah berpengaruh terhadap kinerja guru SMP Negeri seKecamatan Sungai Apit Kabupaten Siak?

\section{METODOLOGI PENELITIAN}

Penelitian ini dilakukan pada SMP Negeri seKecamatan Sungai Apit Kabupaten Siak. Waktu penelitian dilaksanakan pada bulan Maret sampai dengan Juli 2018. Populasi dalam penelitian ini adalah guru SMP Negeri se-Kecamatan Sungai Apit yang berjumlah 85 orang.. Penentuan jumlah sampel dilakukan menggunakan rumus Slovin. Sampel dalam penelitian ini adalah 85 guru dari 108 guru. Teknik yang digunakan dalam pengambilan sampel adalah dengan cara random sampling proporsional.

Teknik pengumpulan data dalam penelitian ini dikumpulkan dengan melakukan penyebaran kuisioner (angket) untuk menilai variabel kinerja guru (Y), komunikasi interpersonal $\left(\mathrm{X}_{1}\right)$, dan supervisi kepala sekolah $\left(\mathrm{X}_{2}\right)$. Teknik analisis data yang dipakai dalam penelitian ini adalah teknik analisis statistik deskriptif dan analisis statistik inferensial. Dalam hal ini, analisis statistik deskriptif dilakukan untuk memberikan gambaran tentang distribusi frekwensi, histogram data, modus, median, nilai rata-rata, simpangan baku, nilai maksimal dan nilai minimal. Analisis statistik inferensial dipakai untuk menguji hipotesis yang sudah dirumuskan sebelumnya. Namun sebelum pengujian persyaratan analisis uji normalitas dan uji linieritas. 


\section{HASIL PENELTIAN DAN PEMBAHASAN}

1. Variabel kinerja guru dalam hal ini diukur dengan 25 item pernyataan. Pernyataan yang dipergunakan berhubungan dengan indikator menguasai bahan ajar, merencanakan proses belajar mengajar, kemampuan melaksanakan dan mengelola proses belajar mengajar, kemampuan melakukan evaluasi atau penilaian, dan kemampuan melaksanakan bimbingan belajar dimana setiap pernyataan diukur dengan skala 1-5. Berdasarkan hasil perhitungan diperoleh skor empirik terendah yang dicapai responden adalah 77 dan skor tertinggi adalah 96 dengan rentang skor sebesar 19. Rata-rata skor adalah 86,29 dengan nilai tengah/median 86,29 dan skor paling sering muncul adalah 87 .

2. Variabel komunikasi interpersonal dalam hal ini diukur dengan 25 item pernyataan. Pernyataan yang dipergunakan berhubungan dengan indikator keterbukaan, perilaku positif, empati, perilaku suportif, dan kesamaan dimana setiap pernyataan diukur dengan skala 1-5. Berdasarkan hasil perhitungan diperoleh skor empirik terendah yang dicapai responden adalah 74 dan skor tertinggi adalah 95 dengan rentang skor sebesar 21. Rata-rata skor adalah 83,61 dengan nilai tengah/median 84 dan skor paling sering muncul adalah 85 .

3. Variabel supervisi kepala sekolah dalam hal ini diukur dengan 26 item pernyataan. Pernyataan yang dipergunakan berhubungan dengan indikator menggugah kesadaran guru, membangun pengertian atas apa yang harus dilakukan, mengawasi jalannya kegiatan pelaksanaan dari hasil yang telah dibicarakan bersama, menilai dan membetulkan yang perlu dijalankan agar lebih baik, dan uji sukses pekerjaan guru dimana setiap pernyataan diukur dengan skala 1-5. Berdasarkan hasil perhitungan diperoleh skor empirik terendah yang dicapai responden adalah 76 dan skor tertinggi adalah 99 dengan rentang skor sebesar 23. Rata-rata skor adalah 89,36 dengan nilai tengah/median 89 dan skor paling sering muncul adalah 89 .

Pengaruh antara ketiga variabel penelitian dapat digambarkan seperti gambar berikut :

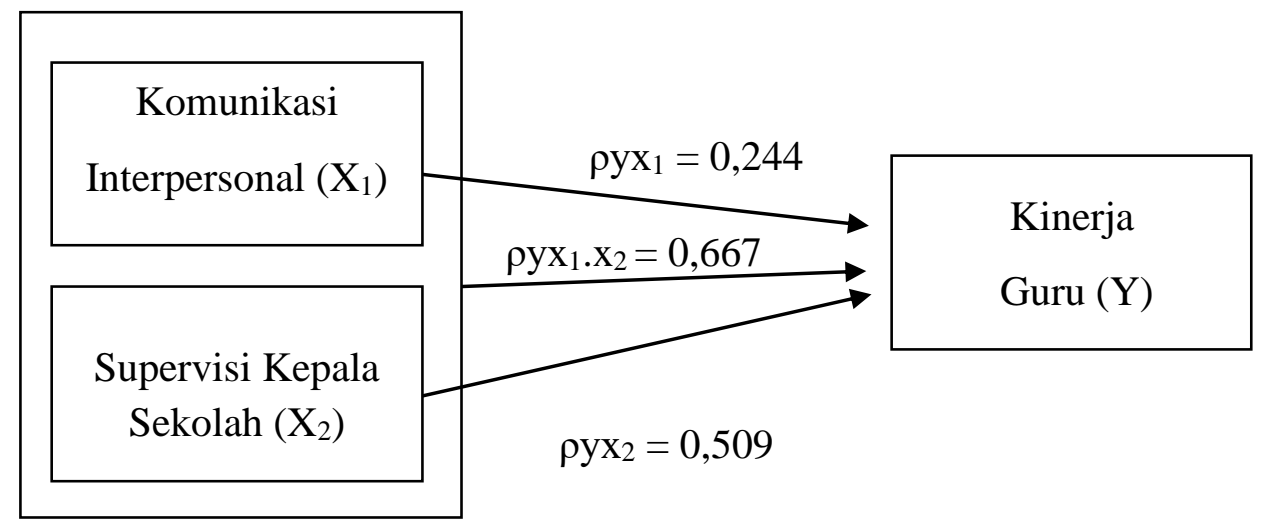

Gambar 1 Pengaruh antar variabel 
Tabel 1Pengaruh Komunikasi Interpersonal $\left(\mathrm{X}_{1}\right)$ dan

Supervisi Kepala Sekolah $\left(\mathrm{X}_{2}\right)$ Terhadap Kinerja Guru (Y)

\begin{tabular}{|l|c|c|c|c|}
\hline \multicolumn{1}{|c|}{ Variabel } & $\begin{array}{c}\text { Standar } \\
\text { Koefisien Beta }\end{array}$ & $\begin{array}{c}\text { Sig }(\mathrm{p}- \\
\text { value) }\end{array}$ & $\begin{array}{c}\text { Kesimpulan } \\
\text { Statistik }\end{array}$ & Pengaruh \\
\hline $\begin{array}{l}\text { Komunikasi } \\
\text { Interpersonal }\left(\mathrm{X}_{1}\right)\end{array}$ & 0,244 & 0,000 & Signifikan & $0,059=5,9 \%$ \\
\hline $\begin{array}{l}\text { Supervisi Kepala } \\
\text { Sekolah }\left(\mathrm{X}_{2}\right)\end{array}$ & 0,509 & 0,000 & Signifikan & $0,259=25,9 \%$ \\
\hline $\begin{array}{l}\mathrm{R}=0,667=\mathrm{R}^{2}=0,446=44,6 \% \\
\text { p.value }=0,000\end{array}$
\end{tabular}

Sumber lampiran SPSS

Pada tabel 1. dapat dijelaskan bahwa pengaruh komunikasi interpersonal dan supervisi kepala sekolah berpengaruh signifikan terhadap kinerja guru sebesar $44,6 \%$, pengaruh komunikasi interpersonal berpengaruh signifikan terhadap kinerja guru sebesar 5,9\%, dan pengaruh Supervisi kepala sekolah berpengaruh signifikan terhadap kinerja guru sebesar $25,9 \%$.

\section{Pengaruh Komunikasi Interpersonal dan Supervisi Kepala Sekolah terhadap Kinerja Guru}

Komunikasi interpersonal dan supervisi kepala sekolah berpengaruh signifikan terhadap kinerja guru sebesar $44,6 \%$. Sisanya 55,4 \% dipengaruhi oleh faktor lain. Ada banyak faktor yang mempengaruhi kinerja guru. Menurut Barnawi dan Mohammad Arifin (2012:43) mengatakan bahwa : "Baik faktor internal maupun faktor eksternal sama-sama membawa dampak terhadap kinerja guru atau prestasi kerja guru. Faktor internal kinerja guru adalah faktor yang datang dari dalam diri guru yang dapat memengaruhi kinerjanya, contohnya ialah kemampuan, ketrampilan, komunikasi interpersonal, kepribadian, persepsi, motivasi menjadi guru, pengalaman lapangan, dan latar belakang keluarga. Faktor eksternal kinerja guru adalah faktor yang datang dari luar guru yang dapat memengaruhi kinerjanya, contohnya ialah (1) gaji; (2) sarana dan prasarana; (3) lingkungan kerja fisik; (4) kepemimpinan.

Menurut Tiffin dan Mc. Cormick dalam Supardi (2013: 53) mengatakan bahwa selain individual, organisasional dan psikologis, faktor lain yang mempengaruhi kinerja guru adalah faktor situasional seperti :

a. Faktor fisik dan pekerjaan terdiri dari : metode kerja, kondisi dan desain perlengkapan kerja, penataan ruang dan lingkungan fisik (penyinaran, temperatur dan fentilasi), (iklim kerja)

b. Faktor sosial dan organisasi, meliputi : peraturan-peraturan organisasi, sifat organisasi, jenis latihan dan pengawasan (supervisi), sistem upah dan lingkungan sosial.

Penelitian lainnya yang juga diyakini relevan dengan analisis masalah dalam penelitian ini adalah penelitian yang dilakukan oleh $\mathrm{H}$. Maryadi Syarif (2011) dengan judul penelitian pengaruh komunikasi interpersonal dan supervisi kepala sekolah terhadap kinerja guru. Hasil penelitian menunjukkan 1) terdapat pengaruh positif komunikasi interpersonal terhadap kinerja guru, 2) terdapat pengaruh positif supervisi 
kepala sekolah terhadap kinerja guru, 3) terdapat pengaruh positif komunikasi interpersonal dan supervisi kepala sekolah secara bersama-sama terhadap kinerja guru. Hasil penelitian ini sesuai dengan pendapat ahli dan hasil penelitian terdahulu, sehingga dapat disimpulkan bahwa "komunikasi interpersonal dan supervisi kepala sekolah berpengaruh terhadap kinerja guru".

\section{Pengaruh Komunikasi Interpersonal terhadap Kinerja Guru}

Komunikasi interpersonal berpengaruh signifikan terhadap kinerja guru sebesar 5,9\%. Sisanya 94,1\% dipengaruhi oleh faktor lain. Hasil penelitian ini sesuai dengan penelitian yang dilakukan oleh Octaviani Darsanti Putri (2012), dengan judul penelitian "pengaruh komunikasi interpersonal dan gaya kepemimpinan kepala sekolah terhadap kinerja guru SMK Negeri 1 Jogonalan Klaten. Hasil penelitian menunjukkan bahwa: (1) Komunikasi interpersonal antara kepala sekolah dan guru SMK Negeri 1 Jogonalan Klaten mempunyai pengaruh positif dan signifikan terhadap Kinerja Guru. Hal ini ditunjukkan dari besarnya nilai $\mathrm{t}$ sebesar 6,503 lebih besar dari t sebesar 2,00. Sedangkan koefisien korelasi sebesar 0,649 dan koefisien determinan sebesar 0,422. Besarnya pengaruh variabel komunikasi interpersonal kepala sekolah dan guru terhadap kinerja guru sebesar 64,7\%, (2) Gaya kepemimpinan kepala sekolah SMK Negeri 1 Jogonalan Klaten berpengaruh positif dan signifikan terhadap Kinerja Guru, dibuktikan dengan nilai t sebesar 4,813 lebih besar dari t 2,00. Koefisien korelasi sebesar 0,534 dan koefisien determinasi sebesar 0,285. Arah pengaruh pada koefisien regresi menunjukkan arah positif, yang artinya semakin tinggi gaya kepemimpinan kepala sekolah, maka semakin tinggi kinerja guru di SMK Negeri 1 Jogonalan Klaten. Gaya kepemimpinan kepala sekolah memberikan sumbangan efektif sebesar 35,3\%, (3) Komunikasi interpersonal dan gaya kepemimpinan kepala sekolah terhadap kinerja guru di SMK Negeri 1 Jogonalan Klaten. Hal ini ditunjukkan dengan $\mathrm{F}$ hitung sebesar 31,920 lebih besar dari $\mathrm{F}$ tabel sebesar 3,17 . Koefisien korelasi sebesar 0,727 dan koefisien determinasi sebesar 0,528. Sedangkan pengaruh variabel Komunikasi interpersonal dan gaya kepemimpinan kepala sekolah tehadap kinerja guru sebesar 52,8\%.

$$
\text { Menurut Winsol dalam }
$$

Wirasasmita (1998:30) menjelaskan bahwa studi komunikasi antar personal efektif berdasarkan teori yang logis meliputi keahlian yang dapat diterapkan pada lingkungannya. Keahlian komunikasi antar personal dan keahlian hubungan manusia (diikuti oleh keahlian lisan) menduduki urutan dalam keenam faktor-faktor terpenting yang diperlukan dalam keberhasilan prestasi kerja, salah satu faktor yang dapat mempengaruhi kinerja guru adalah kemampuan komunikasi interpersonal baik dalam kegiatan pembelajaran maupun hubungan antara guru dengan siswa dan teman sejawat. Dari pendapat ahli dan hasil penelitian yang relevan dapat disimpulkan bahwa komunikasi interpersonal berpengaruh signifikan terhadap kinerja guru.

\section{Pengaruh Supervisi Kepala Sekolah terhadap Kinerja Guru.}

Supervisi kepala sekolah berpengaruh signifikan terhadap kinerja guru sebesar 25,9 \%. Sisanya 24,9\% dipengaruhi oleh faktor lain. Hasil penelitian ini sesuai dengan penelitian yang dilakukan oleh Edi Rismawan (2015). Dengan judul penelitian "pengaruh supervisi kepala sekolah dan 
motivasi berprestasi guru terhadap kinerja mengajar guru. Hasil penelitian menunjukkan bahwa : (1) Supervisi Kepala Sekolah berada pada kategori baik, (2) Motivasi Berprestasi Guru berada pada kategori baik, (3) Kinerja Mengajar Guru berada pada kategori baik,(4) Supervisi Kepala Sekolah (X) berpengaruh positif terhadap Motivasi Berprestasi Guru (Y1), (5) Motivasi Berprestasi Guru (Y1) berpengaruh positif terhadap Kinerja Mengajar Guru (Y2), (6) Supervisi Kepala Sekolah (X) berpengaruh positif terhadap Kinerja Mengajar Guru (Y2), (7) Supervisi Kepala Sekolah (X) dan Motivasi Berprestasi Guru (Y1) secara bersamasama berpengaruh positif terhadap Kinerja Mengajar Guru (Y2).

Menurut pendapat Ivancevich (2007: 101) bahwa "variabel individu utama yang mempengaruhi kinerja mencakup faktor demografis (misalkan usia, ras, jenis kelamin), kemampuan, komunikasi, ketrampilan, persepsi, sikap dan kepribadian".

Menurut Fauza (2010:18) menjelaskan bahwa faktor-faktor yang mempengaruhi kinerja guru adalah tingkat pendidikan guru, supervisi pengajaran, program penataran, iklim yang kondusif, sarana dan prasarana, kondisi fisik dan mental guru, gaya kepemimpinan kepala sekolah, jaminan kesejahteraan, dan kemampuan manajerial kepala sekolah. Dari pendapat diatas dapat disimpulkan bahwa supervisi kepala sekolah berpengaruh signifikan terhadap kinerja guru.

\section{SIMPULAN}

Dari hasil penelitian ini maka diperoleh simpulan yang dirumuskan sebagai berikut :

1. Komunikasi interpersonal dan supervisi kepala sekolah secara bersama berpengaruh positif dan siginifikan terhadap kinerja guru SMP Negeri se-Kecamatan Sungai Apit Kabupaten Siak.

2. Komunikasi interpersonal berpengaruh positif dan signifikan terhadap kinerja guru SMP Negeri se-Kecamatan Sungai Apit Kabupaten Siak.

3. Supervisi kepala sekolah berpengaruh positif dan signifikan terhadap SMP Negeri se-Kecamatan Sungai Apit Kabupaten Siak.

\section{SARAN}

Berdasarkan simpulan dan penelitian ini maka disarankan sebagai berikut :

1. Bagi kepala sekolah di harapkan setelah mengetahui bahwa supervisi untuk guru sangat dibutuhkan dalam peningkatan kinerja guru.

2. Tindak lanjutnya kepada para guru disarankan agar selalu bekerja sama dengan kepala sekolah, melaksanakan tugas sesuai dengan program sekolah sehingga tujuan dapat tercapai dengan baik melalui kinerja yang efektif.

3. Peneliti berikutnya untuk melakukan penelitian lebih lanjut dengan mengkaji faktor-faktor lain yang mempengaruhi kinerja guru sehingga menambah cakrawala dan wawasan lebih luas. diharapkan peran sesama peneliti bidang pendidikan untuk dapat memberikan koreksi, kritik, dan saran demi meningkatkan kesempurnaan dari hasil penelitian ini, sehingga manfaat dari hasil penelitian ini dapat diimplikasikan secara nyata dan berguna dimasa yang akan datang. 


\section{DAFTAR PUSTAKA}

Anwar Prabu Mangkunegara. (2003). Perencanaan dan Pengembangan Sumber Daya Manusia. Bandung: Refika Aditama

Ary H. Gunawan, (2000). Administrasi Sekolah: Administrasi Pendidikan Mikro. Jakarta: Rineka Cipta

A.W. Widjaja. (2002). Komunikasi dan Hubungan Masyarakat. Jakarta : PT. Bumi Aksara

Dadang Suhardan, (2010). Supervisi Professonal (Layanan Dalam Meningkatkan Mutu Pembelajaran di Era Otonomi Daerah). Bandung: Alfabeta

Devito, A. Joseph. (2011). Komunikasi Antarmanusia. Tangerang : Karisma Publishing Group.

E. Mulyasa. (2002). Manajemen Berbasis Sekolah. Bandung : PT Remaja Rosda Karya

E. Mulyasa, (2004). Kurikulum Berbasis Kompetensi. Bandung: Remaja Rosdakarya Offset

Henry Simamora. (2004). Manajemen Sumber Daya Manusia. Edisi Ke3. STIE YKPN. Yogyakarta

Kartini, Kartono. (2005). Pemimpin dan Kepemimpinan. Jakarta: Rajawali Pers

Mulyasa, E. (2007). Menjadi Guru Profesional menciptakan Pembelajaran Kreatif dan
Menyenangkan. Bandung : Rosdakarya

Sahertian. (2008). Konsep Dasar \& Teknik Supervisi Pendidikan. Jakarta: PT Rineka Cipta

Surya Dharma, (2005). Manajemen Kinerja (Falsafah teori dan penerapannya).Yogyakarta: Pustaka Pelajar

Uno Hamzah B. (2007). Teori Motivasi dan Pengukurannya: Analisis di Bidang Pendidikan. Bumi Aksara : Jakarta

Wibisono, Dermawan. (2006). Manajemen Kinerja. Penerbit Erlangga : Jakarta

Wibowo, (2011). Manajemen Kinerja. Jakarta : Raja Grafindo Persada 